\title{
Reversible Removal of Intermixed Shallow States by Light Soaking in Multication Mixed Halide Perovskite Films
}

Dengyang Guo, ${ }^{\dagger}$ Zahra Andaji Garmaroudi, ${ }^{\ddagger}$ Mojtaba Abdi-Jalebi, ${ }^{\ddagger 0}$ Samuel D. Stranks, ${ }^{\ddagger 0}$ and Tom J. Savenije*ti

${ }^{\dagger}$ Department of Chemical Engineering, Delft University of Technology, $2629 \mathrm{HZ}$ Delft, The Netherlands

${ }^{\ddagger}$ Cavendish Laboratory, JJ Thomson Avenue, Cambridge CB3 OHE, United Kingdom

Supporting Information

ABSTRACT: The highest reported efficiencies of metal halide perovskite (MHP) solar cells are all based on mixed perovskites, such as (FA,MA,Cs)$\mathrm{Pb}\left(\mathrm{I}_{1-x} \mathrm{Br}_{x}\right)_{3}$. Despite demonstrated structural changes induced by light soaking, it is unclear how the charge carrier dynamics are affected across this entire material family. Here, various (FA,MA,Cs) $\mathrm{Pb}\left(\mathrm{I}_{1-x} \mathrm{Br}_{x}\right)_{3}$ perovskite films are light-soaked in nitrogen, and changes in optoelectronic properties are investigated through time-resolved microwave conductivity (TRMC) and optical and structural techniques. To fit the TRMC decay kinetics obtained for pristine (FA,MA,Cs) $\mathrm{Pb}\left(\mathrm{I}_{1-x} \mathrm{Br}_{x}\right)_{3}$ for various excitation densities, additional shallow states have to be included, which are not required for describing TRMC traces of single-cation MHPs. These shallow states can, independently of $x$, be removed by light soaking, which leads to a reduction in the imbalance between the diffusional motion of electrons and holes. We interpret the shallow states as a result of initially well-intermixed halide distributions, which upon light soaking segregate into domains with distinct band gaps.
$\mathrm{P}$ erovskite solar cells have achieved the fastest increase in power conversion efficiencies (PCEs) in solar cell research history, exceeding now $24 \% .{ }^{1,2}$ Recent records of perovskite solar cells are all based on mixed cation-mixed halide perovskites (MCMHPs)., 3 The advantages of MCMHPs in comparison with single-cation perovskites are the tunable band gaps and more stable, black phase, ${ }^{4,5}$ while the main drawback of these perovskites is related to lightinduced phase segregation. ${ }^{6,7}$ Several LS studies on MCMHP solar cells have been carried out, which revealed a variety of changes in $V_{\mathrm{oc}} I_{\mathrm{sc}}$ and FF. ${ }^{4,8-14}$ To explain the changes in device performance, various groups studied structural and optical changes in bare MHP layers induced by light soaking (LS). Initially, phase segregation, which leads to I-rich and Brrich domains, was reported in both $\operatorname{MAPb}\left(\mathrm{I}_{1-x} \mathrm{Br}_{x}\right)_{3}$ and $\mathrm{FAPb}\left(\mathrm{I}_{1-x} \mathrm{Br}_{x}\right)_{3}$ as determined by either photoluminescence (PL) emission, ${ }^{7,15-17}$ differential absorption spectra, ${ }^{13}$ or XRD. ${ }^{18-20}$ The addition of Cs stabilizes (FA,MA)Pb$\left(\mathrm{I}_{1-x} \mathrm{Br}_{x}\right)_{3}{ }^{4}$ and increases the PCE output. ${ }^{21}$ However, from the work by Tress et al., ${ }^{8}$ phase segregation still occurs in (FA,MA,Cs) $\mathrm{Pb}\left(\mathrm{I}_{1-x} \mathrm{Br}_{x}\right)_{3}$, as concluded from a wavelength shift in PL upon LS. Recent work using micro- and nanofocus XRD techniques from Jones et al. revealed structural inhomogeneity in both MCMHP and $\mathrm{MAPbI}_{3}{ }^{22}$ Tsai et al. found local lattice distortion in (FA,MA,Cs) $\mathrm{PbI}_{3}$ and attributed the improvement in device performance upon LS to interface modification and release of local distortion. ${ }^{23}$

The studies above relate structural inhomogeneity to the device performance. However, how the charge carriers in MCMHPs are affected by this structural change is less well studied. In this work, we use optical and time-resolved microwave conductivity (TRMC) $)^{24-27}$ techniques to investigate the influence of LS on charge carrier dynamics in various $\left(\mathrm{FA}_{0.79} \mathrm{MA}_{0.15} \mathrm{Cs}_{0.06}\right) \mathrm{Pb}\left(\mathrm{I}_{1-x} \mathrm{Br}_{x}\right)_{3}$ with $x$ ranging from 0 to 1 . Surprisingly, in contrast to most other studied MHPs, mathematical analysis of the decay kinetics of the pristine layers with $0.2 \leq x \leq 0.8$ requires the presence of shallow states. ${ }^{28}$ We link these states to a mostly well intermixed halide distribution, leading to a varying energy landscape in the bulk. Interestingly, these shallow states are seemingly removed upon LS, which we attribute to the conversion of these states into distinct iodide-rich, low-band-gap domains. The fact that the layers return to their original structure after storage in the dark for over 1 week reveals that for these MCMHPs the presence

Received: August 8, 2019

Accepted: September 5, 2019

Published: September 5, 2019 

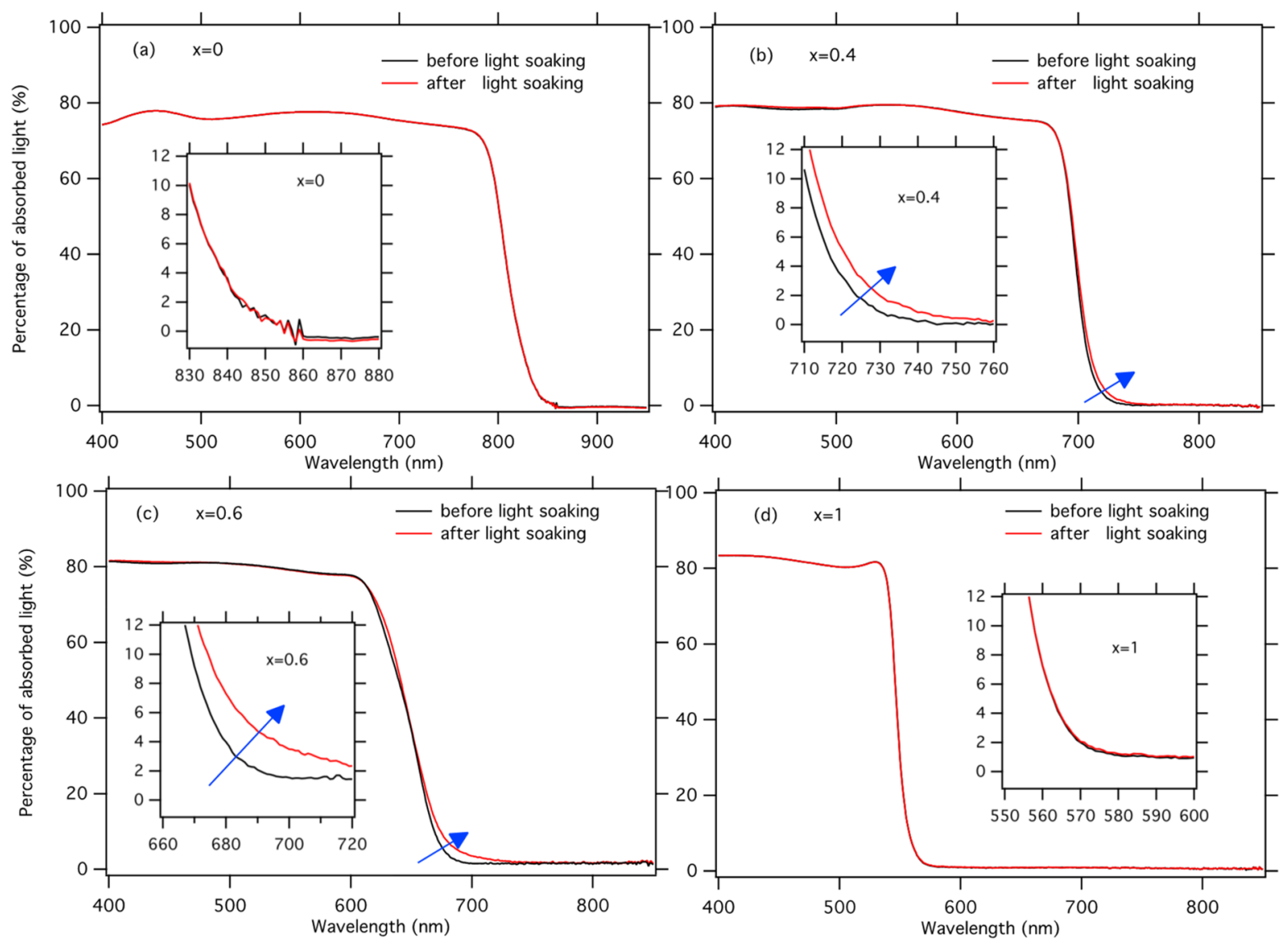

Figure 1. Absorptance spectra before and after $\mathrm{LS}$ in $\mathrm{N}_{2}$ for $\left(\mathrm{FA}_{0.79} \mathrm{MA}_{0.15} \mathrm{Cs}_{0.06}\right) \mathrm{Pb}\left(\mathrm{I}_{1-x} \mathrm{Br}_{x}\right)_{3}$ with $x=0,0.4,0.6$, and 1. The blue arrows indicate the shift due to the LS. For comparison, the effect of $L S$ on $M A P b\left(I_{0.6} B r_{0.4}\right)_{3}$ is shown in Figure $S 3 b$. The insets are magnifications to show the subtle shift due to the LS.

of shallow states (i.e., well intermixed halide distributions) is thermodynamically the most stable conformation.

Throughout this work, we studied bare $\left(\mathrm{FA}_{0.79} \mathrm{MA}_{0.15} \mathrm{Cs}_{0.06}\right)$ $\mathrm{Pb}\left(\mathrm{I}_{1-x} \mathrm{Br}_{x}\right)_{3}$ films with $x$ varying between 0 and 1 deposited by spin-coating on quartz substrates without any exposure to air or moisture. SEM images of these layers are provided in Figure $S 1$, showing similar grain sizes for all values of $x$, in agreement with the reported better crystallization of MCMHPs than single-cation analogues. ${ }^{4}$ For a number of samples, XRD spectra are provided in Figure S2, showing the specific features of the perovskite structure. LS was accomplished by illumination for $30 \mathrm{~min}$ with a white light LED with an intensity equivalent to AM1.5 in $\mathrm{N}_{2}$. To study the structural reorganization in $\left(\mathrm{FA}_{0.79} \mathrm{MA}_{0.15} \mathrm{Cs}_{0.06}\right) \mathrm{Pb}\left(\mathrm{I}_{1-x} \mathrm{Br}_{x}\right)_{3}$ upon LS, we first measured the absorptance spectra, as shown in Figure 1 , and detailed band-edge information from photothermal deflection spectroscopy (PDS) (Figure S3a). In Figure 1b,c, only a subtle shift of the band-edge to longer wavelengths for $x$ $=0.4$ and 0.6 upon LS is visible, even if the LS treatment is prolonged to overnight exposure. The spectra of nonmixed halides $\left(\mathrm{FA}_{0.79} \mathrm{MA}_{0.16} \mathrm{Cs}_{0.05}\right) \mathrm{PbI}_{3}$ and $\left(\mathrm{FA}_{0.79} \mathrm{MA}_{0.16} \mathrm{Cs}_{0.05}\right)$ $\mathrm{PbBr}_{3}$ (Figure 1a,d) do not show these optical changes, indicating that no structural reorganization occurs upon LS. In contrast, the substantial shift in absorption onset of the singlecation $\mathrm{MAPb}\left(\mathrm{I}_{0.6} \mathrm{Br}_{0.4}\right)_{3}$ shown in Figure S3b supports the idea that the structural reorganization in the triple-cation perovskite upon LS is significantly slower than that in monocation perovskites, in line with previous observations. ${ }^{29}$
Figure 2 collects the corresponding PL spectra upon $532 \mathrm{~nm}$ $\mathrm{CW}$ laser excitation for the same set of MHPs. Figure $2 \mathrm{~b}$ shows that the $\mathrm{PL}$ emission at $715 \mathrm{~nm}$ of $\left(\mathrm{FA}_{0.79} \mathrm{MA}_{0.16} \mathrm{Cs}_{0.05}\right) \mathrm{Pb}$ $\left(\mathrm{I}_{0.6} \mathrm{Br}_{0.4}\right)_{3}$ gradually reduces and a second band appears at 760 $\mathrm{nm}$ upon LS. In Figure 2c, similar gradual PL changes for $x=$ 0.6 upon LS are observed. Despite significant differences in the initial band gaps of $x=0.4,0.6$, and 0.8 (Figure S4a), the PL emission wavelengths upon LS are all close to that of $x=0.2$ (shown in Figure S4b), in agreement with previous studies on similar mixed MHPs. ${ }^{16,17,30-33}$ Note that this second PL emission wavelength is still $\sim 50 \mathrm{~nm}$ blue shifted with respect to that of $\left(\mathrm{FA}_{0.79} \mathrm{MA}_{0.16} \mathrm{Cs}_{0.05}\right) \mathrm{PbI}_{3}$, excluding the formation of bromide-free regions (see Figure 2a). Interestingly, the total PL intensity of both PL bands remains within a factor of 2 constant for $x=0.4$ and 0.6 , which is in large contrast with MHPs light soaked under humid conditions. ${ }^{25,34}$ The observed PL changes are different from those of single-cation MHPs like $\operatorname{MAPb}\left(\mathrm{I}_{1-x} \mathrm{Br}_{x}\right)_{3}$ and $\mathrm{FAPb}\left(\mathrm{I}_{1-x} \mathrm{Br}_{x}\right)_{3}$. In MAPb $\left(\mathrm{I}_{1-x} \mathrm{Br}_{x}\right)_{3}$, with $x=0.4$ or 0.6 , a short illumination period leads to a clear PL shift in combination with formation of a shorter-wavelength peak, ${ }^{7}$ which are attributed to I-rich and Br-enriched domains, respectively, as reported previously. ${ }^{18,33}$ In order to find out if our observed changes in MCMHP are driven by the presence of a mixture of iodide and bromide, we measured the PL of $\left(\mathrm{FA}_{0.79} \mathrm{MA}_{0.16} \mathrm{Cs}_{0.05}\right) \mathrm{PbI}_{3}$ and $\left(\mathrm{FA}_{0.79} \mathrm{MA}_{0.16} \mathrm{Cs}_{0.05}\right) \mathrm{PbBr}_{3}$ upon $\mathrm{LS}$, as shown in Figures $2 \mathrm{a}$ and $1 \mathrm{~d}$. The decrease in PL intensity is comparable to that observed in single-cation MHPs. ${ }^{35}$ However, because the maximum PL intensity for these monocation MHPs remains at the same wavelength, we 

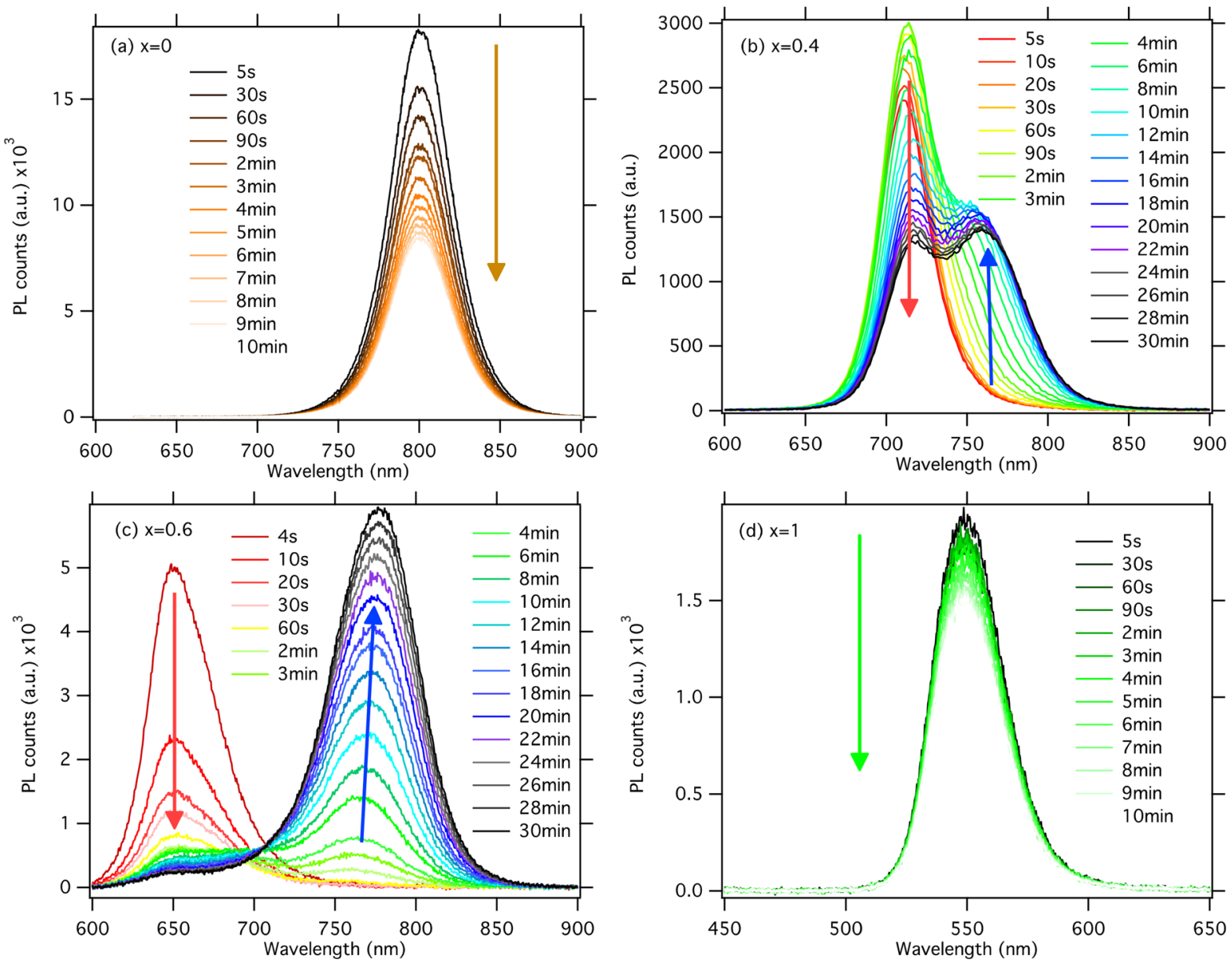

Figure 2. PL spectra of $\left(\mathrm{FA}_{0.79} \mathrm{MA}_{0.15} \mathrm{Cs}_{0.06}\right) \mathrm{Pb}\left(\mathrm{I}_{1-x} \mathrm{Br}_{x}\right)_{3}$ with $x=0,0.4,0.6$, and 1 in time upon $\mathrm{LS}$ in $\mathrm{N}_{2}\left(532 \mathrm{~nm} \mathrm{laser,} \sim 60 \mathrm{~mW} / \mathrm{cm}^{2}\right)$

conclude that the structural reorganization is propelled by the halide mixture. However, from the profound changes between single-cation and multication perovskites upon LS, we conclude that the multication system slows down the phase segregation tremendously, in line with previous observations. ${ }^{35}$

To find out whether the bulk crystalline structure is affected by LS, we performed XRD measurements before and after LS of the $x=0.4$ sample, shown in Figure S2. There are no shifts or additional peaks visible in the XRD pattern upon LS, confirming that the bulk crystalline structure is not affected and that the size and/or proportion of the iodide-enriched domains are far lower and not detectable in these experiments in comparison to the bulk. The amount of $\mathrm{PbI}_{2}$ is not affected by the LS, as evidenced in Figure S2. The change in XRD patterns reported for single-cation MHPs supports the idea that the MCMHPs are relatively more stable against LS. ${ }^{33,36}$

To study the effect of LS on the charge carrier dynamics in $\left(\mathrm{FA}_{0.79} \mathrm{MA}_{0.15} \mathrm{Cs}_{0.06}\right) \mathrm{Pb}\left(\mathrm{I}_{1-x} \mathrm{Br}_{x}\right)_{3}$ with $0 \leq x \leq 1$, we carried out TRMC measurements and recorded traces before and after the LS treatment, as shown in Figure 3. For comparison, TRMC traces for a single-cation perovskite, i.e., MAPb$\left(\mathrm{I}_{0.6} \mathrm{Br}_{0.4}\right)_{3}$, are also included. TRMC results for $x=0.2$ and 0.8 are provided in Figure S5. The transients show a rapid rise due to formation of excess charge carriers by the laser pulse, while the decay of the signal represents how mobile carriers get immobilized or undergo recombination. The excitation densities range from $10^{14}$ to $10^{16} \mathrm{~cm}^{-3}$, calculated from the laser intensity, the sample thickness, and the fraction of absorbed light at the excitation wavelength. To facilitate comparison of traces acquired using different intensities, the photoconductance signals are normalized to the number of absorbed photons. The first important observation is that upon LS the charge carrier lifetimes become shorter for, in particular, the samples with $0.4 \leq x \leq 0.6$. For the latter samples and to a lesser extent $x=0.2$ and 0.8 , the TRMC tails exhibit the same slope independent of the laser intensity in this log-linear representation. This feature is not observed for MHPs with only a single halide, i.e., $\left(\mathrm{FA}_{0.79} \mathrm{MA}_{0.16} \mathrm{Cs}_{0.05}\right) \mathrm{PbI}_{3}$ and $\left(\mathrm{FA}_{0.79} \mathrm{MA}_{0.16} \mathrm{Cs}_{0.05}\right) \mathrm{PbBr}_{3}$ (Figure 3b,e, left panels), and also for MHPs with only a single cation, $\mathrm{MAPb}\left(\mathrm{I}_{0.6} \mathrm{Br}_{0.4}\right)_{3}$ (Figure $3 \mathrm{a}$, left panel). This implies that the occurrence of these TRMC tails is somehow linked to the presence of both mixed cations and mixed halides. Interestingly, this behavior is absent after $30 \mathrm{~min}$ of LS, as clearly visible in the right panels of Figure 3. Much longer LS treatments $(17 \mathrm{~h})$ show essentially the same effect, as shown in Figure S6. The samples show almost complete recovery after storage in the glovebox in the dark for over 1 week, especially regarding the tails, as shown in Figure S7.

In order to extract kinetic parameters from the TRMC results, we apply a kinetic model recently reported by Hutter et $\mathrm{al}^{26}$ that successfully described the formation and decay of the light-induced charge carriers in $\mathrm{MAPbI}_{3}$ and other MHPs. ${ }^{37-41}$ In that model, two decay pathways for charge carriers were included: band-to-band recombination, with rate constant $k_{2}$, and trap-mediated recombination. However, that model was 

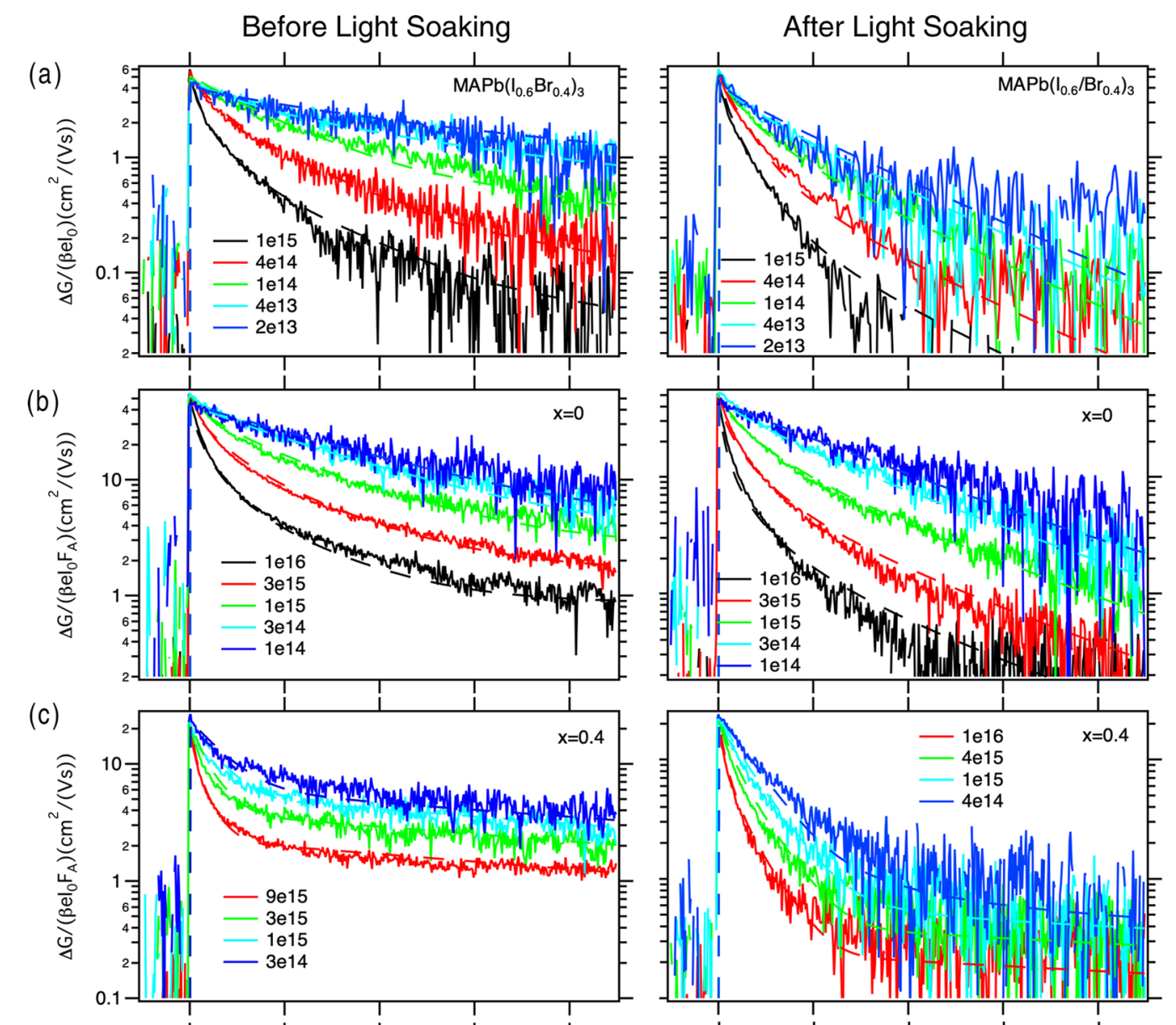

(d)
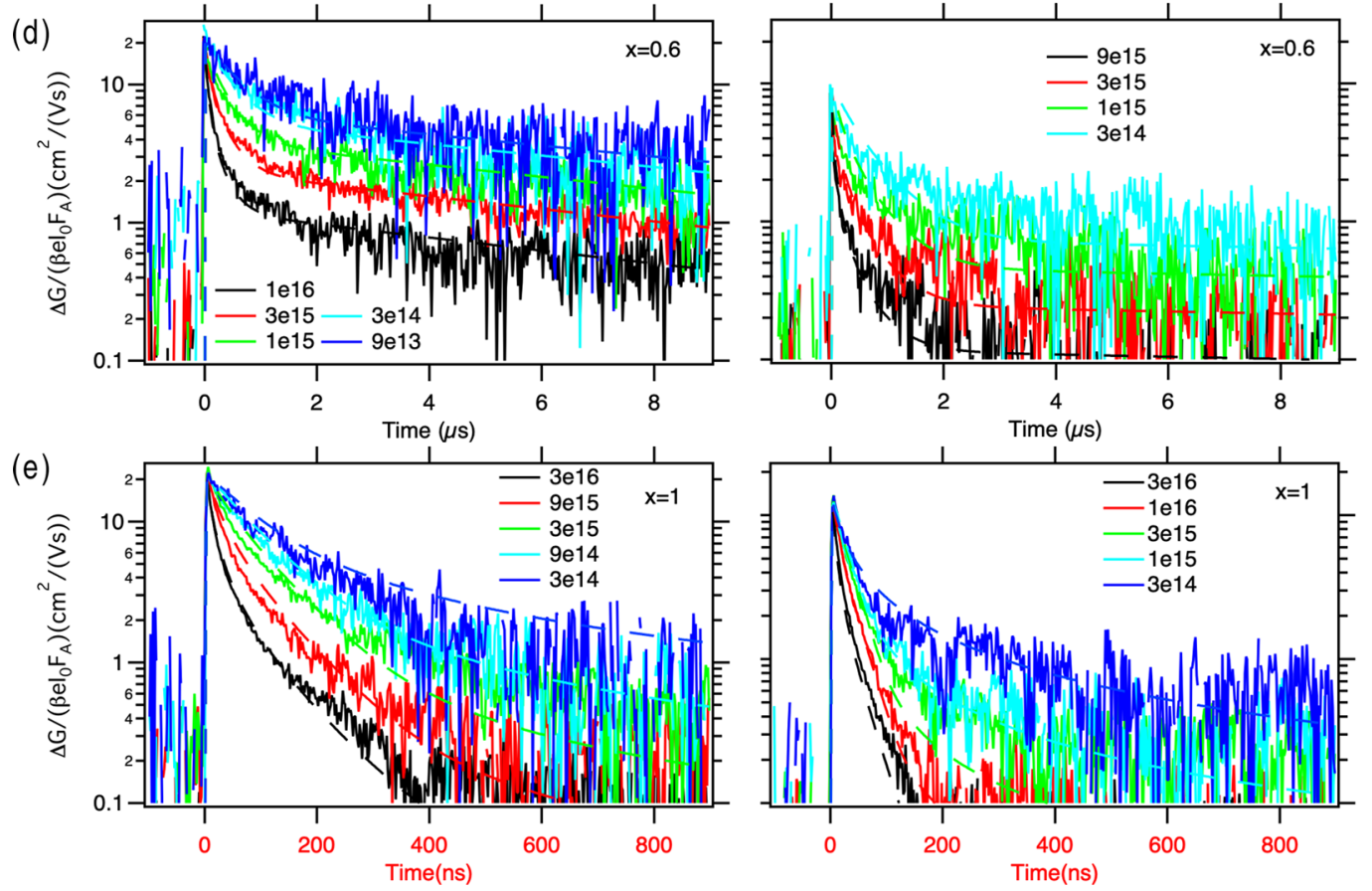

Figure 3. TRMC traces of $\mathrm{MAPb}\left(\mathrm{I}_{0.6} \mathrm{Br}_{0.4}\right)_{3}$ (a) and $\left(\mathrm{FA}_{0.79} \mathrm{MA}_{0.15} \mathrm{Cs}_{0.06}\right) \mathrm{Pb}\left(\mathrm{I}_{1-x} \mathrm{Br}_{x}\right)_{3}$ for $(\mathrm{b}) \mathrm{x}=\mathbf{0}$, (c) 0.4, (d) 0.6, and (e) 1 before (left panels) and after (right) LS. The analogues $x=0.2$ and 0.8 are shown for comparison in Figure S5. Solid lines are the experimental traces, and dashed lines are the results of the fits. Note that panel (e) has a different time scale of $1 \mu \mathrm{s}$. The samples were all excited by laser pulses at $500 \mathrm{~nm}$ with excitation intensities leading to charge carrier densities ranging from $10^{14}$ to $10^{16} \mathrm{~cm}^{-3}$, and specific densities are given in the annotations.

not capable of describing the kinetics of the pristine MHMCPs adequately, implying that at least one additional or different decay pathway is required. Previously, a similar transient behavior was observed for charge carriers in $\mathrm{FAPbI}_{3}$ at low 
temperatures. $^{42}$ Moreover, Azulay and co-workers recently evoked the presence of shallow states to explain their scanning tunneling results. ${ }^{28}$ Therefore, we included in our kinetic model an additional pathway, in which mobile charges are temporarily immobilized with a first-order rate constant $k_{\mathrm{s}}$ and thermally released with $k_{\mathrm{r}}$, as is depicted in Figure 4a. Note
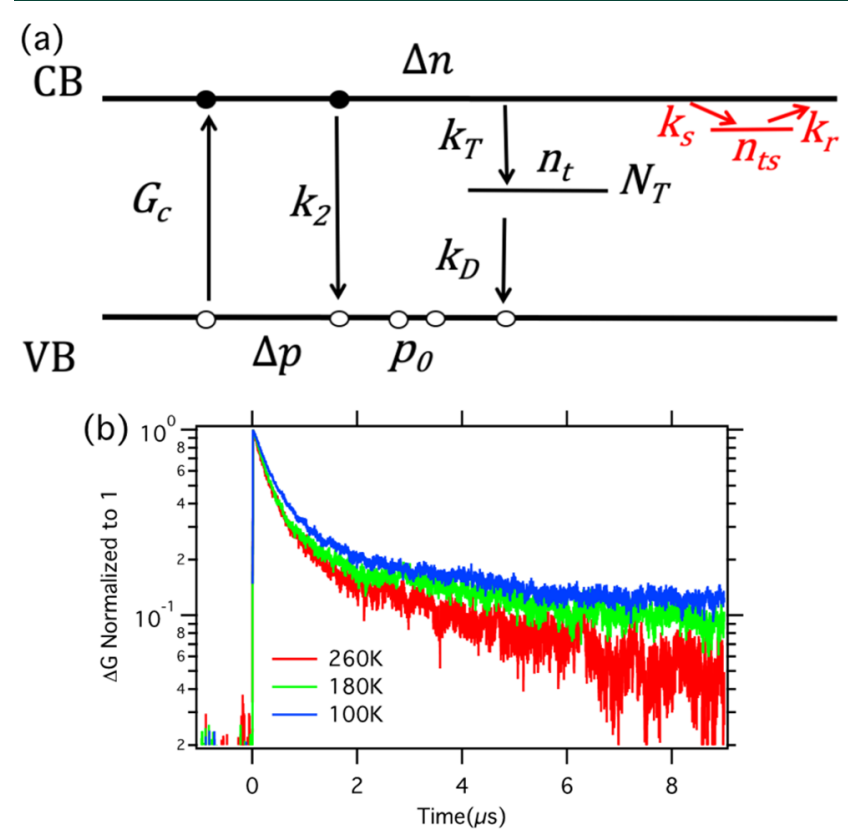

Figure 4. (a) Kinetic model describing the charge carrier dynamics in MHPs with the following decay pathways: band-to-band recombination with rate $k_{2}$; deep trap-assisted recombination with trapping rate $k_{\mathrm{T}}$ and depopulation rate $k_{\mathrm{D}}$; and immobilization in shallow states with trapping rate $k_{\mathrm{s}}$ and thermal release rate $k_{\mathrm{r}}$. (b) Temperature-dependent TRMC traces of sample $x=0.4$ recorded at an excitation density of $5.4 \times 10^{14} \mathrm{~cm}^{-3}$. that immobilized carriers ${ }^{36}$ do not contribute to the conductance during the period in which they reside in these states. This additional pathway could be substantiated by shallow defect states but also by, e.g., low crystalline domains in which carriers have a reduced mobility. The corresponding set of differential equations and a more complete description of our fitting procedure are provided in the Supporting Information (eqs S1-S4). The occupancy of these shallow states is expected to be heavily temperature dependent. The lower the temperature, the more charges that will reside in these shallow states, preventing them from recombining, which would translate into longer charge carrier lifetimes. Note that with TRMC we probe both electrons and holes, weighed with their respective mobility. We measured $x=0.4$ at different temperatures, as shown in Figure $4 b$, showing a gradually smaller slope of the tails with lower temperatures. This is in line with the idea that with lower temperatures one of the carriers remains trapped for longer and longer periods, and with that, recombination to the ground state is reduced.

We applied the modified model to fit all of the TRMC traces, and results are added to Figures 3 and S5, showing excellent agreement between the model and data (see also Figure S8 for different representations). The extracted kinetic parameters are listed in Table $S 1$ and are also presented in Figures 5 and S9. Figure 5a shows the sum of mobilities, which reduces gradually from around $66 \mathrm{~cm}^{2} /(\mathrm{V} \mathrm{s})$ for $x=0$ to 33 $\mathrm{cm}^{2} /(\mathrm{V} \mathrm{s})$ for $x=1$. This reduction upon increasing $\mathrm{Br}$ content in $\left(\mathrm{FA}_{0.79} \mathrm{MA}_{0.15} \mathrm{Cs}_{0.06}\right) \mathrm{Pb}\left(\mathrm{I}_{1-x} \mathrm{Br}_{x}\right)_{3}$ is in line with that reported for $\left(\mathrm{FA}_{0.83} \mathrm{Cs}_{0.17}\right) \mathrm{Pb}\left(\mathrm{I}_{1-x} \mathrm{Br}_{x}\right)_{3}{ }^{24,43}$ From Figure $5 \mathrm{~b}$, one can see that before LS the band-to-band recombination rate, $k_{2}$, increases gradually with $\mathrm{Br}$ content, which is similar to that reported for $\mathrm{FAPb}\left(\mathrm{I}_{1-x} \mathrm{Br}_{x}\right)_{3}$ measurements. ${ }^{15}$ Upon LS, $k_{2}$ remains approximately the same for $x \leq 0.4$, while $k_{2}$ increases for $0.6 \leq x \leq 1$. Figure $5 \mathrm{c}$ shows a gradual increase in trapping and release rates by shallow states with higher $\mathrm{Br}$ content. Most importantly, upon LS, both rates decrease substantially, which implies that both carriers remain now in the valence and
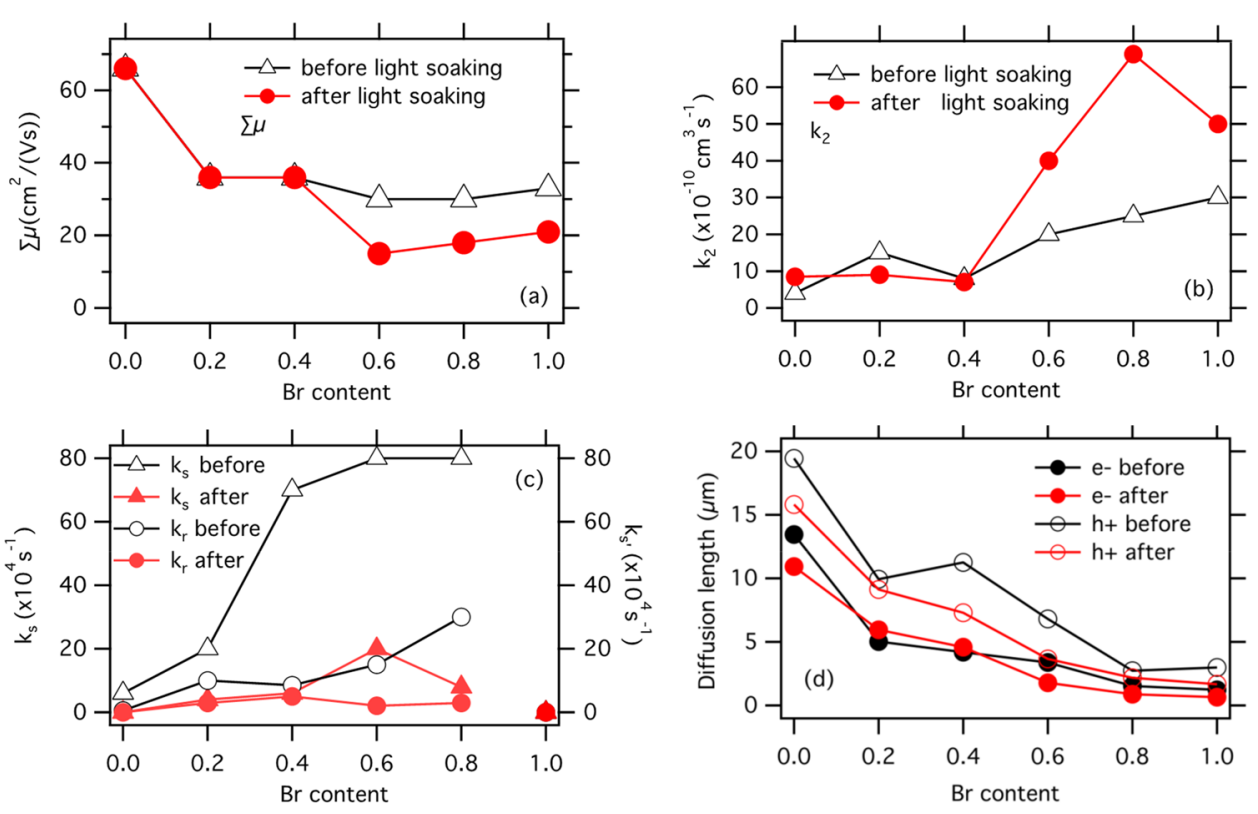

Figure 5. (a) Sum of charge carrier mobilities, $\sum \mu$, before (black hollow triangles) and after (red solid circles) LS versus Br fraction. (b) Band-to-band recombination rate, $k_{2}$. (c) Trapping and escaping rates, $k_{\mathrm{s}}$ and $k_{\mathrm{r}}$ of the shallow states. (d) Diffusion lengths of electrons and holes calculated from the lifetimes upon excitation at $3 \times 10^{14} \mathrm{~cm}^{-3}$ derived from Figure $S 10$. 
conduction band and can recombine. The overall effect is that the charge carrier lifetimes reduce especially for higher intensities in combination with the disappearance of the parallel tails. Important to note here is that the gradual change of the dynamic parameters with $x$ cannot be explained by the morphology of the MCMHP layers because the grain sizes are rather similar, as is clear from the SEM images shown in Figure S1.

To picture the effect of the LS on the electronic properties of the MCMHPs, we calculated the charge carrier diffusion lengths before and after LS, as shown in Figure 5d. We note here that we assume that the material is unintentionally $p$ doped; however, the opposite case is also possible. ${ }^{44}$ These diffusion lengths are calculated on the basis of the charge carrier mobilities given in Table S1 via the EinsteinSmoluchowski relation and the lifetimes derived from the rate constants as shown in Figure S10 using a laser intensity leading to an initial excitation density of $3 \times 10^{14} \mathrm{~cm}^{-3}$. In particular, for (FA,MA,Cs) $\mathrm{Pb}\left(\mathrm{I}_{1-x} \mathrm{Br}_{x}\right)_{3}$ with $x=0.4$, there is an imbalance between the diffusion of electrons and holes because one of the carriers is temporarily immobilized. It can be expected that in solar cells this imbalance gives rise to additional space charge fields blocking efficient collection, and in LEDs, this imbalance would be detrimental to the charge injection. Upon LS, the shallow states vanish and the decay of electrons and holes becomes almost identical (see Figure S10), and hence, the imbalance in diffusion lengths is largely diminished. However, apart from this halide redistribution, in a complete cell also, ion migration might occur upon LS, affecting the internal electric field in the device and with that its performance. ${ }^{45}$

To understand the origin of the shallow sub-band-gap states and the effect of the LS on the charge dynamics, we first consider the facts that those states require the presence of both mixed cations and mixed halides. We speculate that a nonuniform distribution of cations and halides leads to intermixed shallow states, in line with previous claims. ${ }^{28}$ Consequently, a varying energy landscape is created with shallow levels close to the band edge. Correa-Baena et al. demonstrated recently that neither cations nor halides are homogeneously spread over MCMHP films. ${ }^{46}$ Furthermore, Rehman et al. reported that $\mathrm{FAPb}\left(\mathrm{I}_{1-x} \mathrm{Br}_{x}\right)_{3}$ with $x$ between 0.3 and 0.5 are amorphous in nature, and mobilities in those materials are lower than $2 \mathrm{~cm}^{2} /(\mathrm{V} \mathrm{s})$. Temporal localization of excess charge carriers in such intermixed shallow states is fully consistent with the kinetic model shown in Figure 4a by realizing that the long-lived TRMC signals originate from the mobile counter charges.

As has been argued previously by Hoke et al., LS leads to reorganization of the halides, resulting in local higher concentrations of iodide atoms. ${ }^{18}$ As suggested by Knight et $\mathrm{al}^{34}$ and Belisle et al., ${ }^{36}$ the mechanism of this reorganization process is mediated by the localization of positive charges. Randomly moving iodide atoms cluster near the positive charges, providing a thermodynamic driving force to form iodide-rich domains. However, we conclude that for our (FA,MA,Cs) $\mathrm{Pb}\left(\mathrm{I}_{1-x} \mathrm{Br}_{x}\right)_{3}$ films this occurs at the intermixed shallow states. As a result, we suggest that the shallow states of intermixed halides convert into distinct iodide-rich, low-bandgap domains, as is evident from our TRMC and optical data. Hence, this process is different than that for the single-cation MHPs: although the formation of iodide domains is accelerated by defects, these appear preferentially at the illuminated site. ${ }^{16,17}$ The conversion process induced by LS has different effects on the optoelectronic properties depending on $x$ : While for $0.2 \leq x \leq 0.4$ found $\mu$ and $k_{2}$ values remain constant, for $0.6 \leq x \leq 0.8$, LS leads to a decrease of $\mu$ and increasing $k_{2}$ values. To explain these observations, we note that these fitting parameters are the results of treating the materials as homogeneous media. This results in effective values for $\mu$ and $k_{2}$. However, the low-band-gap, iodide-rich domains have a substantial energetic offset with respect to the bulk: close to $0.3 \mathrm{eV}$ for $x=0.6$ as deduced from the PL data. Hence, upon optical excitation of layers with $0.6 \leq x \leq 0.8$, the segregated domains may mediate fast, higher-order charge carrier decay as excitations transfer to the lower-gap iodide-rich domains. Finally, upon prolonged storage in the dark, the MCMHPs regain their original thermodynamically most favorable structure probably due to entropic reasons. ${ }^{47}$ Thus, the shallow states corresponding to intermixed halides are reformed, suggesting that no motion of the cations is involved in the LS process.

In this work, we studied how the dynamics of charge carriers change upon $\mathrm{LS}$ in various (FA,MA,Cs) $\mathrm{Pb}\left(\mathrm{I}_{1-x} \mathrm{Br}_{x}\right)_{3}$ films by $\mathrm{PL}$, optical absorption, XRD, and TRMC. First, in such MCMHPs, decay pathways of photoexcited charge carriers not only include recombination via band-to-band and deep traps but also immobilization in and thermal escape from shallow states independent of $x$. We speculate that a nonuniform distribution of cations and halides in the (FA,MA,Cs) $\mathrm{Pb}$ $\left(\mathrm{I}_{1-x} \mathrm{Br}_{x}\right)_{3}$ films could lead to these intermixed shallow states. The shallow states cause imbalanced electron and hole diffusion lengths. Second, by LS, these states convert into distinct iodide-rich, low-band-gap domains. For LS samples with $0.2 \leq x \leq 0.4$, the shallow states are virtually absent, while the bulk properties including the mobility and band-to-band recombination remain the same. Only for samples with $0.6 \leq x$ $\leq 0.8$ do these low-band-gap domains lead to enhanced higherorder recombination, which will negatively affect the photovoltaic performance. Finally, we suggest that by optimizing the constituent ratios it is possible to further improve the mixed perovskite solar cells by making the MCMHP film free of shallow states, which induce the halide segregation.

\section{ASSOCIATED CONTENT}

\section{S Supporting Information}

The Supporting Information is available free of charge on the ACS Publications website at DOI: 10.1021/acsenergylett.9b01726.

Additional optical and TRMC measurements, XRD patterns, and absolute values of the dynamic rates (PDF)

\section{AUTHOR INFORMATION}

\section{Corresponding Author}

*E-mail: T.J.Savenije@tudelft.nl.

ORCID $\odot$

Mojtaba Abdi-Jalebi: 0000-0002-9430-6371

Samuel D. Stranks: 0000-0002-8303-7292

Tom J. Savenije: 0000-0003-1435-9885

Notes

The authors declare no competing financial interest. 


\section{ACKNOWLEDGMENTS}

D.G. acknowledges the CSC (China Scholarship Council) for funding, File No. 201504910812. Z.A.-G. acknowledges funding from a Winton Studentship and ICON Studentship from the Lloyd's Register Foundation. M.A.-J. thanks Cambridge Materials Limited and EPSRC (Grant Number EP/ M005143/1) for their funding and technical support. S.D.S. acknowledges the Royal Society and Tata Group (UF150033) for funding.

\section{REFERENCES}

(1) Kojima, A.; Teshima, K.; Shirai, Y.; Miyasaka, T. Organometal Halide Perovskites as Visible-Light Sensitizers for Photovoltaic Cells. J. Am. Chem. Soc. 2009, 131, 6050-6051.

(2) NREL. Research Cell Efficiency Records. National Center for Photovoltaics, https://www.nrel.gov/pv/assets/pdfs/best-researchcell-efficiencies.20190802.pdf (accessed Jul 17, 2018).

(3) Ono, L. K.; Juarez-Perez, E. J.; Qi, Y. Progress on Perovskite Materials and Solar Cells with Mixed Cations and Halide Anions. ACS Appl. Mater. Interfaces 2017, 9, 30197-30246.

(4) Saliba, M.; Matsui, T.; Seo, J.-Y.; Domanski, K.; Correa-Baena, J.-P.; Nazeeruddin, M. K.; Zakeeruddin, S. M.; Tress, W.; Abate, A.; Hagfeldt, A.; et al. Cesium-Containing Triple Cation Perovskite Solar Cells: Improved Stability, Reproducibility and High Efficiency. Energy Environ. Sci. 2016, 9, 1989-1997.

(5) Jesper Jacobsson, T.; Correa-Baena, J.-P.; Pazoki, M.; Saliba, M.; Schenk, K.; Grätzel, M.; Hagfeldt, A. Exploration of the Compositional Space for Mixed Lead Halogen Perovskites for High Efficiency Solar Cells. Energy Environ. Sci. 2016, 9, 1706-1724.

(6) deQuilettes, D. W.; Zhang, W.; Burlakov, V. M.; Graham, D. J.; Leijtens, T.; Osherov, A.; Bulović, V.; Snaith, H. J.; Ginger, D. S.; Stranks, S. D. Photo-Induced Halide Redistribution in OrganicInorganic Perovskite Films. Nat. Commun. 2016, 7, 11683.

(7) Yoon, S. J.; Draguta, S.; Manser, J. S.; Sharia, O.; Schneider, W. F.; Kuno, M.; Kamat, P. V. Tracking Iodide and Bromide Ion Segregation in Mixed Halide Lead Perovskites during Photoirradiation. ACS Energy Lett. 2016, 1, 290-296.

(8) Tress, W.; Yavari, M.; Domanski, K.; Yadav, P.; Niesen, B.; Correa Baena, J. P.; Hagfeldt, A.; Graetzel, M. Interpretation and Evolution of Open-Circuit Voltage, Recombination, Ideality Factor and Subgap Defect States during Reversible Light-Soaking and Irreversible Degradation of Perovskite Solar Cells. Energy Environ. Sci. 2018, 11, 151-165.

(9) Hu, J.; Gottesman, R.; Gouda, L.; Kama, A.; Priel, M.; Tirosh, S.; Bisquert, J.; Zaban, A. Photovoltage Behavior in Perovskite Solar Cells under Light-Soaking Showing Photoinduced Interfacial Changes. ACS Energy Lett. 2017, 2, 950-956.

(10) Gil-Escrig, L.; Momblona, C.; La-Placa, M. G.; Boix, P. P.; Sessolo, M.; Bolink, H. J. Vacuum Deposited Triple-Cation MixedHalide Perovskite Solar Cells. Adv. Energy Mater. 2018, 8, 1703506.

(11) Duong, T.; Wu, Y. L.; Shen, H.; Peng, J.; Fu, X.; Jacobs, D.; Wang, E. C.; Kho, T. C.; Fong, K. C.; Stocks, M.; et al. Rubidium Multication Perovskite with Optimized Bandgap for PerovskiteSilicon Tandem with over 26\% Efficiency. Adv. Energy Mater. 2017, 7, 1700228.

(12) Jiang, Q.; Zhang, L.; Wang, H.; Yang, X.; Meng, J.; Liu, H.; Yin, Z.; Wu, J.; Zhang, X.; You, J. Enhanced Electron Extraction Using $\mathrm{SnO} 2$ for High-Efficiency Planar-Structure $\mathrm{HC}(\mathrm{NH} 2) 2 \mathrm{PbI} 3$-Based Perovskite Solar Cells. Nat. Energy 2017, 2, 16177.

(13) Samu, G. F.; Janáky, C.; Kamat, P. V. A Victim of Halide Ion Segregation. How Light Soaking Affects Solar Cell Performance of Mixed Halide Lead Perovskites. ACS Energy Lett. 2017, 2, 18601861.

(14) Nie, W.; Blancon, J.-C.; Neukirch, A. J.; Appavoo, K.; Tsai, H.; Chhowalla, M.; Alam, M. A.; Sfeir, M. Y.; Katan, C.; Even, J.; et al. Light-Activated Photocurrent Degradation and Self-Healing in Perovskite Solar Cells. Nat. Commun. 2016, 7, 11574.
(15) Rehman, W.; Milot, R. L.; Eperon, G. E.; Wehrenfennig, C.; Boland, J. L.; Snaith, H. J.; Johnston, M. B.; Herz, L. M. ChargeCarrier Dynamics and Mobilities in Formamidinium Lead MixedHalide Perovskites. Adv. Mater. 2015, 27, 7938-7944.

(16) Ruth, A.; Brennan, M. C.; Draguta, S.; Morozov, Y. V.; Zhukovskyi, M.; Janko, B.; Zapol, P.; Kuno, M. Vacancy-Mediated Anion Photosegregation Kinetics in Mixed Halide Hybrid Perovskites: Coupled Kinetic Monte Carlo and Optical Measurements. ACS Energy Lett. 2018, 3, 2321-2328.

(17) Barker, A. J.; Sadhanala, A.; Deschler, F.; Gandini, M.; Senanayak, S. P.; Pearce, P. M.; Mosconi, E.; Pearson, A. J.; Wu, Y.; Srimath Kandada, A. R.; et al. Defect-Assisted Photoinduced Halide Segregation in Mixed-Halide Perovskite Thin Films. ACS Energy Lett. 2017, 2, 1416-1424.

(18) Hoke, E. T.; Slotcavage, D. J.; Dohner, E. R.; Bowring, A. R.; Karunadasa, H. I.; McGehee, M. D. Reversible Photo-Induced Trap Formation in Mixed-Halide Hybrid Perovskites for Photovoltaics. Chem. Sci. 2015, 6, 613-617.

(19) Barker, A. J.; Sadhanala, A.; Deschler, F.; Gandini, M.; Senanayak, S. P.; Pearce, P. M.; Mosconi, E.; Pearson, A. J.; Wu, Y.; Srimath Kandada, A. R. et al. Defect-Assisted Photoinduced Halide Segregation in Mixed-Halide Perovskite Thin Films. ACS Energy Lett. 2017, 2, 1416-1424.

(20) Hu, M.; Bi, C.; Yuan, Y.; Bai, Y.; Huang, J. Stabilized Wide Bandgap MAPbBrxI3-x Perovskite by Enhanced Grain Size and Improved Crystallinity. Adv. Sci. 2016, 3, 1500301.

(21) Zheng, X.; Wu, C.; Jha, S. K.; Li, Z.; Zhu, K.; Priya, S. Improved Phase Stability of Formamidinium Lead Triiodide Perovskite by Strain Relaxation. ACS Energy Lett. 2016, 1, 1014-1020.

(22) Jones, T. W.; Osherov, A.; Alsari, M.; Sponseller, M.; Duck, B. C.; et al. Lattice Strain Causes Non-Radiative Losses in Halide Perovskites. Energy Environ. Sci. 2019, 12, 596-25 See the Electronic Supporting Information

(23) Tsai, H.; Asadpour, R.; Blancon, J. C.; Stoumpos, C. C.; Durand, O.; Strzalka, J. W.; Chen, B.; Verduzco, R.; Ajayan, P. M.; Tretiak, S.; et al. Light-Induced Lattice Expansion Leads to HighEfficiency Perovskite Solar Cells. Science 2018, 360, 67-70.

(24) Herz, L. M. Charge-Carrier Mobilities in Metal Halide Perovskites: Fundamental Mechanisms and Limits. ACS Energy Lett. 2017, 2, 1539-1548

(25) Brenes, R.; Guo, D.; Osherov, A.; Noel, N. K.; Eames, C.; Hutter, E. M.; Pathak, S. K.; Niroui, F.; Friend, R. H.; Islam, M. S.; et al. Metal Halide Perovskite Polycrystalline Films Exhibiting Properties of Single Crystals. Joule 2017, 1, 155-167.

(26) Hutter, E. M.; Eperon, G. E.; Stranks, S. D.; Savenije, T. J. Charge Carriers in Planar and Meso-Structured Organic-Inorganic Perovskites: Mobilities, Lifetimes, and Concentrations of Trap States. J. Phys. Chem. Lett. 2015, 6, 3082-3090.

(27) Wehrenfennig, C.; Eperon, G. E.; Johnston, M. B.; Snaith, H. J.; Herz, L. M. High Charge Carrier Mobilities and Lifetimes in Organolead Trihalide Perovskites. Adv. Mater. 2014, 26, 1584-1589.

(28) Azulay, D.; Levine, I.; Gupta, S.; Barak-Kulbak, E.; Bera, A.; San, G.; Simha, S.; Cahen, D.; Millo, O.; Hodes, G.; et al. On the Influence of Multiple Cations on the In-Gap States and Phototransport Properties of Iodide-Based Halide Perovskites. Phys. Chem. Chem. Phys. 2018, 20, 24444-24452.

(29) Braly, I. L.; Stoddard, R. J.; Rajagopal, A.; Uhl, A. R.; Katahara, J. K.; Jen, A. K. Y. K.; Hillhouse, H. W. Current Induced Phase Segregation in Mixed Halide Hybrid Perovskites and Its Impact on Two-Terminal Tandem Solar Cell Design. ACS Energy Lett. 2017, 2, 1841.

(30) Abdi-Jalebi, M.; Andaji-Garmaroudi, Z.; Cacovich, S.; Stavrakas, C.; Philippe, B.; Richter, J. M.; Alsari, M.; Booker, E. P.; Hutter, E. M.; Pearson, A. J.; et al. Maximizing and Stabilizing Luminescence from Halide Perovskites with Potassium Passivation. Nature 2018, 555, 497-501.

(31) Slotcavage, D. J.; Karunadasa, H. I.; McGehee, M. D. LightInduced Phase Segregation in Halide-Perovskite Absorbers. ACS Energy Lett. 2016, 1, 1199-1205. 
(32) Gualdrón-Reyes, A. F.; Yoon, S. J.; Barea, E. M.; Agouram, S.; Muñoz-Sanjosé, V.; Meléndez, Á. M.; Niño-Gómez, M. E.; MoraSeró, I. Controlling the Phase Segregation in Mixed Halide Perovskites through Nanocrystal Size. ACS Energy Lett. 2019, 4, 54-62.

(33) Brennan, M. C.; Draguta, S.; Kamat, P. V.; Kuno, M. LightInduced Anion Phase Segregation in Mixed Halide Perovskites. ACS Energy Lett. 2018, 3, 204-213.

(34) Knight, A. J.; Wright, A. D.; Patel, J. B.; Mcmeekin, D. P.; Snaith, H. J.; Johnston, M. B.; Herz, L. M. Electronic Traps and Phase Segregation in Lead Mixed-Halide Perovskite. ACS Energy Lett. 2019, $4,75-84$.

(35) Motti, S. G.; Meggiolaro, D.; Barker, A. J.; Mosconi, E.; Perini, C. A. R.; Ball, J. M.; Gandini, M.; Kim, M.; De Angelis, F.; Petrozza, A. Controlling Competing Photochemical Reactions Stabilizes Perovskite Solar Cells. Nat. Photonics 2019, 13, 532-539.

(36) Belisle, R. A.; Bush, K. A.; Bertoluzzi, L.; Gold-Parker, A.; Toney, M. F.; McGehee, M. D. Impact of Surfaces on Photoinduced Halide Segregation in Mixed-Halide Perovskites. ACS Energy Lett. 2018, 3, 2694-2700.

(37) Hutter, E. M.; Gélvez-Rueda, M. C.; Bartesaghi, D.; Grozema, F. C.; Savenije, T. J. Band-Like Charge Transport in $\mathrm{Cs}_{2} \mathrm{AgBiBr}_{6}$ and Mixed Antimony-Bismuth $\mathrm{Cs}_{2} \mathrm{AgBi}_{1-\mathrm{x}} \mathrm{Sb}_{\mathrm{x}} \mathrm{Br}_{6}$ Halide Double Perovskites. ACS Omega 2018, 3, 11655-11662.

(38) Hu, Y.; Hutter, E. M.; Rieder, P.; Grill, I.; Hanisch, J.; Aygüler, M. F.; Hufnagel, A. G.; Handloser, M.; Bein, T.; Hartschuh, A.; et al. Understanding the Role of Cesium and Rubidium Additives in Perovskite Solar Cells: Trap States, Charge Transport, and Recombination. Adv. Energy Mater. 2018, 8, 1703057.

(39) Chandrashekar, S.; Abdi-Jalebi, M.; Sutton, R. J.; Hutter, E. M.; Savenije, T. J.; Stranks, S. D.; Snaith, H. J. Vapour-Deposited Cesium Lead Iodide Perovskites: Microsecond Charge Carrier Lifetimes and Enhanced Photovoltaic Performance. ACS Energy Lett. 2017, 2, 1901-1908.

(40) Pérez-del-Rey, D.; Forgács, D.; Hutter, E. M.; Savenije, T. J.; Nordlund, D.; Schulz, P.; Berry, J. J.; Sessolo, M.; Bolink, H. J. Strontium Insertion in Methylammonium Lead Iodide: Long Charge Carrier Lifetime and High Fill-Factor Solar Cells. Adv. Mater. 2016, 28, 9839-9845.

(41) Guo, D.; Bartesaghi, D.; Wei, H.; Hutter, E. M.; Huang, J.; Savenije, T. J. Photoluminescence from Radiative Surface States and Excitons in Methylammonium Lead Bromide Perovskites. J. Phys. Chem. Lett. 2017, 8, 4258-4263.

(42) Wright, A. D.; Milot, R. L.; Eperon, G. E.; Snaith, H. J.; Johnston, M. B.; Herz, L. M. Band-Tail Recombination in Hybrid Lead Iodide Perovskite. Adv. Funct. Mater. 2017, 27, 1700860.

(43) Wright, A. D.; Verdi, C.; Milot, R. L.; Eperon, G. E.; PérezOsorio, M. A.; Snaith, H. J.; Giustino, F.; Johnston, M. B.; Herz, L. M. Electron-Phonon Coupling in Hybrid Lead Halide Perovskites. Nat. Commun. 2016, 7, 11755.

(44) Miller, E. M.; Zhao, Y.; Mercado, C. C.; Saha, S. K.; Luther, J. M.; Zhu, K.; Stevanović, V.; Perkins, C. L.; Van De Lagemaat, J. Substrate-Controlled Band Positions in CH3NH3PbI3perovskite Films. Phys. Chem. Chem. Phys. 2014, 16, 22122-22130.

(45) Domanski, K.; Roose, B.; Matsui, T.; Saliba, M.; Turren-Cruz, S. H.; Correa-Baena, J. P.; Carmona, C. R.; Richardson, G.; Foster, J. M.; De Angelis, F.; et al. Migration of Cations Induces Reversible Performance Losses over Day/Night Cycling in Perovskite Solar Cells. Energy Environ. Sci. 2017, 10, 604-613.

(46) Correa-Baena, J.-P.; Luo, Y.; Brenner, T. M.; Snaider, J.; Sun, S.; Li, X.; Jensen, M. A.; Hartono, N. T. P.; Nienhaus, L.; Wieghold, S.; et al. Homogenized Halides and Alkali Cation Segregation in Alloyed Organic-Inorganic Perovskites. Science 2019, 363, 627-631.

(47) Ball, J. M.; Petrozza, A. Defects in Perovskite-Halides and Their Effects in Solar Cells. Nat. Energy 2016, 1, 16149. 